\title{
Diagnosis and management of septal deviation and nasal valve collapse - a survey of Canadian otolaryngologists
}

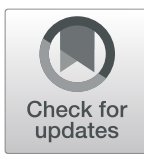

\author{
Yiqiao Wang ${ }^{1}$ and James P. Bonaparte ${ }^{2^{*}}$ (D)
}

\begin{abstract}
Background: Management of nasal valve collapse (NVC) in patients with a septal deviation can be challenging. Our objective was to determine the opinions of Canadian Otolaryngologists regarding the diagnosis and management of nasal obstruction in patients with septal deviation and NVC.

Methods: A twenty-question survey was developed for the purpose of our study. Questions were divided into the following areas: diagnosis, management and prognosis. We included all otolaryngologists who were members of the Canadian Society of Otolaryngology.

Results: The response rate to our survey was $18 \%$. The most commonly identified cause of a failed septoplasty was incomplete septoplasty (41.9\%), followed by nasal valve collapse (25.6\%). The Cottle manoeuvre (62.8\%) and visual inspection (39.5\%) were noted to be the most important diagnostic tools for external and internal NVC respectively. However, physicians often rely on a variable number of different examinations when making a diagnosis of nasal valve collapse. When evaluating which patients with a septal deviation also required nasal valve surgery, 27.9\% of responders believed the current physical examination methods provided a high accuracy, while 55.8\% indicated moderate accuracy and $16.3 \%$ indicated low accuracy. Compared to other subspecialties in Otolaryngology, Facial Plastic and Reconstruction Surgeons noted higher septoplasty failure rates in patients with co-morbid NVC.

Conclusions: NVC is an important concern for otolaryngologists performing septoplasty. Although most physicians believe that the physical exam provides a moderate effectiveness when predicting who requires a functional rhinoplasty, diagnostic methods used for NVC is varied and inconsistent.
\end{abstract}

Keywords: Septoplasty, Nasal obstruction, Nasal valve collapse, Survey

\section{Introduction}

Septal deviation is a common cause of nasal obstruction, present in up to $80 \%$ of the general population [1]. However, many cases of septal deviation are asymptomatic, and the degree or severity of deviation has little to no correlation with the degree of obstruction $[2,3]$. This paradox creates a diagnostic dilemma for some patients and surgeons. Not all patients, regardless of symptoms

\footnotetext{
* Correspondence: DrJames.Bonaparte@gmail.com Presented at the Canadian Society of Otolaryngology $72^{\text {nd }}$ Annual Meeting, Quebec City, QC, Canada

${ }^{2}$ Department of Otolaryngology - Head and Neck Surgery, Senior Clinical Investigator, The Ottawa Hospital Research Institute, University of Ottawa, Ottawa, Canada

Full list of author information is available at the end of the article
}

demonstrate an improvement as patient satisfaction after septoplasty ranges between 65 to $80 \%$ [4].

One potential cause of treatment failure may be misidentification of other comorbid causes of nasal obstruction, specifically nasal valve collapse (NVC) $[5,6]$. Concurrent NVC is often viewed as an important feature to identify prior to a septoplasty to prevent need for revision surgery $[7,8]$. Clinicians have developed several physical examinations to assess and diagnose NVC [5, 9-11]. However, a consensus statement by the American Academy of Otolaryngology - Head and Neck Surgery (AAO-HNS) states that although many such tests are available, there is no gold standard [10]. Common tests for diagnosis include the Cottle manoeuvre (cheek displaced laterally with the fingers) and the modified Cottle manoeuvre (ear curette used to

(C) The Author(s). 2019 Open Access This article is distributed under the terms of the Creative Commons Attribution 4.0 International License (http://creativecommons.org/licenses/by/4.0/), which permits unrestricted use, distribution, and 
support the lower lateral cartilage). Bachman's Maneuver, although less commonly used and often confused with the Modified Cottle Maneuver, involves digital pressure on the tip of the nose, pushing the nose upward in the sagittal plane (ie a pig nose appearance).

Due to these challenges, a better understanding of how otolaryngologists approach septal deviation and NVC will help guide development of guidelines as well as future research into the area. Therefore, the objective of this study was to determine the opinions of Canadian Otolaryngologists regarding the diagnosis and management of nasal obstruction with septal deviation and NVC. Our secondary objective was to evaluate differences between sub-specialists.

\section{Methods}

\section{Survey}

Research Ethics Board approval was obtained through The Ottawa Hospital (Protocol \#20160194-01H). Our team constructed a twenty-question survey for our study. The survey was developed initially from personal experience and peer reviewed literature, then pilot tested with members of the University of Ottawa, Department of Otolaryngology. Once completed and revised, feedback from the American Academy of Otolaryngology Head and Neck Surgery (AAO-HNS) Rhinology committee was provided. Further revisions were then made, and a final survey was approved. The survey was divided into the following areas: diagnosis, management, and prognosis. All questions were mandatory, and additional responses could be added if required.

\section{Data collection}

Eligible participants were otolaryngologists who were members of the Canadian Society of Otolaryngology Head and Neck Surgery (CSOHNS). Two email invitations were sent to all members in January and April 2017, which included the survey link and a description of the project. The survey closed in August 2017. Consent to participate was implicit on response, and all responses were gathered anonymously. A third party recognized survey website (www.surveymonkey.com) was used for data collection and storage.

\section{Data analysis}

All information was treated confidentially. Data was exported to excel (Microsoft $\odot$, 2018) and Minitab 18 (Minitab Inc) for analysis. Survey data that included continuous data was assessed using an ANOVA for normally distributed data and Kruskal-Wallis test for non-normally distributed data. Categorical data was analysed using Chi-square testing. Significance was defined as $p \leq 0.05$.
Table 1 Demographics

\begin{tabular}{lll}
\hline Variable & Count & \% total \\
\hline Total Respondents & 86 & 100 \\
Speciality & & \\
$\quad$ General & 48 & 55.8 \\
FPRS & 18 & 20.9 \\
Rhinology & 20 & 23.3 \\
Other & 0 & 0.0 \\
Experience (years) & & \\
$<5$ & 30 & 34.9 \\
5-10 & 24 & 27.9 \\
$10-15$ & 8 & 9.3 \\
15-20 & 4 & 4.7 \\
$>20$ & 20 & 23.3 \\
Practice & & \\
Hospital & 26 & 30.2 \\
Office & 22 & 25.6 \\
Community & 38 & 44.2 \\
\hline
\end{tabular}

\section{Results}

\section{Demographics}

Demographic data is outlined in Table 1. Eighty-six otolaryngologists responded to our survey from a total of 489 invitations (18\%). Respondents were General Otolaryngologists, Facial Plastics and Reconstruction Surgeons (FPRS), and Rhinologists, with the majority having less than 10 years of experience. Type of practice was evenly distributed between community, office and hospital.

\section{Diagnosis}

Surgeons utilized up to seven different physical examination or historical findings when identifying internal and external nasal valve collapse (Table 2). Visual inspection was identified as the most common test for the diagnosis of both internal and external NVC.

Table 2 Methods Used to diagnose Nasal Valve Collapse in a typical clinical encounter

\begin{tabular}{|c|c|c|c|c|}
\hline \multirow[t]{2}{*}{ Examination* } & \multicolumn{2}{|c|}{ Internal } & \multicolumn{2}{|c|}{ External } \\
\hline & $\mathrm{n}$ & \% Total & $\mathrm{n}$ & $\%$ total \\
\hline Visual Inspection & 80 & $93.0 \%$ & 78 & $90.7 \%$ \\
\hline Cottle Maneuver & 48 & $55.8 \%$ & 33 & $38.4 \%$ \\
\hline Modified Cottle Maneouvre & 34 & $39.5 \%$ & 31 & $36.0 \%$ \\
\hline Failed Septoplasty & 38 & $44.2 \%$ & 20 & $23.3 \%$ \\
\hline Bachman's & 10 & $11.6 \%$ & 10 & $11.6 \%$ \\
\hline Trial of BreathRight & 2 & $2.3 \%$ & 0 & $0.0 \%$ \\
\hline Fiber-optic Nasolaryngoscopy & 0 & $0.0 \%$ & 0 & $0.0 \%$ \\
\hline Acoustic Rhinometry & 2 & $2.3 \%$ & 2 & $2.3 \%$ \\
\hline
\end{tabular}

* responders to this question were allowed to chose all the physical examinations they used in a typical clincal encounter 
Table 3 List the physical examination method that you rely on the most for the diagnosis of Nasal Valve Collapse

\begin{tabular}{llllll}
\hline & \multicolumn{2}{l}{ Internal } & & \multicolumn{2}{l}{ External } \\
\cline { 2 - 3 } \cline { 6 - 7 } Visual Inspection & $\mathrm{n}$ & $\%$ Total & & $\mathrm{n}$ & $\%$ Total \\
Cottle Maneuver & 34 & $39.5 \%$ & & 2 & $2.3 \%$ \\
Modified Cottle Maneouvre & 22 & $25.6 \%$ & & 6 & $7.0 \%$ \\
Failed Septoplasty & 6 & $7.0 \%$ & & 10 & $11.6 \%$ \\
Bachman's & 0 & $0.0 \%$ & & 4 & $4.7 \%$ \\
General Physical Exam & 0 & $0.0 \%$ & & 6 & $7.0 \%$ \\
Experience & 2 & $2.3 \%$ & & 0 & $0.0 \%$ \\
Fiber-optic Nasolaryngoscopy & 0 & $0.0 \%$ & & 0 & $0.0 \%$ \\
Breathe Right Trial & 0 & $0.0 \%$ & & 0 & $0.0 \%$ \\
History Alone & 0 & $0.0 \%$ & & 0 & $0.0 \%$ \\
Other & 0 & $0.0 \%$ & & 4 & $4.7 \%$ \\
\hline
\end{tabular}

However, the Cottle Manoeuvre was most commonly identified as the most important single test for the diagnosis of external NVC. In terms of internal NVC, both visual inspection and the modified Cottle maneuver we identified as the most important examination at near similar rates (Table 3). $52.2 \%$ of all respondents identified visible valve collapse on inspiration as the most important finding that suggested the need for nasal valve repair at time of septoplasty, with rates of $66.7 \%$ for General Otolaryngologists and $44.4 \%$ for FPRS (Table 4). In contrast, the majority of Rhinologists (37.5\%) noted that static narrowing of the nasal valve was the most important finding (Table 4). Furthermore, with respect to diagnostic accuracy (the ability to predict which patients with a septal deviation also required nasal valve surgery), most physicians believed the physical exam provided moderate accuracy. There was a trend towards FPRS indicating a higher level of accuracy compared to other specialists however this did not reach statistical significance (Table 5, $p=0.23$ ).

\section{Management}

All respondents performed septoplasties, with a mean (standard deviation) of 71.2 (60.7) surgeries per year (Table 6). Similarly, $74.4 \%$ of respondents performed nasal valve surgeries, with a mean of 18.4(17.2) surgeries per year (Table 6). Significantly more Rhinologists and FPRS perform nasal valve surgery $(p<0.001)$, and FPRS perform significantly more yearly procedures $(p=0.004)$. Respondents indicated that $25.4 \%$ of patients with symptomatic septal deviation had comorbid NVC (Table 6). Interestingly, $79.1 \%$ of surgeons indicated that less than $50 \%$ of patients with evidence of NVC and septal deviation required a functional rhinoplasty in addition to septoplasty, while $9.3 \%$ of surgeons indicated all patients with evidence of NVC required a functional rhinoplasty (Table 7). There was a significant difference of opinions between subspecialties regarding percentage of patients who require nasal valve surgery $(p=0.001$, Table 7$)$. In addition, statistically significant differences were found between FPRS and other surgeons in terms of the percentage of patients who require a functional rhinoplasty $(p=0.001$, Table 6).

\section{Prognosis}

According to our survey, the most commonly identified cause of a failed septoplasty was inadequate septoplasty followed by untreated NVC (Table 8). Interestingly, results were similar for all subspecialties apart from $22.2 \%$ of FPRS indicating that a caudal septal deviation was one most common cause. Respondents noted that in patients with evidence of septal deviation and NVC, the mean (SD) percentage of patients who do not improve after a septoplasty alone was 33.7 (24.8) \%. Failure in this case was defined as the patient not indicating significant improvement in breathing at 3 months follow-up (Table 6). There was also a significant difference between specialities regarding the failure rate of septoplasty alone $(p=0.012$, Table 6$)$.

Table 4 Most Important finding indicating need for Functional Rhinoplasty

\begin{tabular}{|c|c|c|c|c|c|c|c|c|}
\hline & \multicolumn{2}{|c|}{ Total } & \multicolumn{2}{|c|}{ General } & \multicolumn{2}{|c|}{ FPRCS } & \multicolumn{2}{|c|}{ Rhinology } \\
\hline & $n$ & $\%$ & $n$ & $\%$ & $n$ & $\%$ & $n$ & $\%$ \\
\hline Collapse on Inspiration & 42 & $48.8 \%$ & 32 & $66.7 \%$ & 8 & $44.4 \%$ & 2 & $10.0 \%$ \\
\hline Cottle Maneuver & 6 & $7.0 \%$ & 4 & $8.3 \%$ & 0 & $0.0 \%$ & 2 & $10.0 \%$ \\
\hline Modified Cottle & 2 & $2.3 \%$ & 2 & $4.2 \%$ & 0 & $0.0 \%$ & 0 & $0.0 \%$ \\
\hline Static Narrow Nasal Valve & 8 & $9.3 \%$ & 0 & $0.0 \%$ & 2 & $11.1 \%$ & 6 & $30.0 \%$ \\
\hline Severe Nasal Symptoms & 12 & $14.0 \%$ & 6 & $12.5 \%$ & 2 & $11.1 \%$ & 4 & $20.0 \%$ \\
\hline Location of Septal Deviation & 4 & $4.7 \%$ & 2 & $4.2 \%$ & 2 & $11.1 \%$ & 0 & $0.0 \%$ \\
\hline Intra-op findings & 2 & $2.3 \%$ & 0 & $0.0 \%$ & 0 & $0.0 \%$ & 2 & $10.0 \%$ \\
\hline Failure of Septoplasty & 4 & $4.7 \%$ & 0 & $0.0 \%$ & 4 & $22.2 \%$ & 0 & $0.0 \%$ \\
\hline No Answer & 6 & $7.0 \%$ & 2 & $4.2 \%$ & 0 & $0.0 \%$ & 4 & $20.0 \%$ \\
\hline
\end{tabular}


Table 5 Accuracy of physical exam to determine who requires surgery

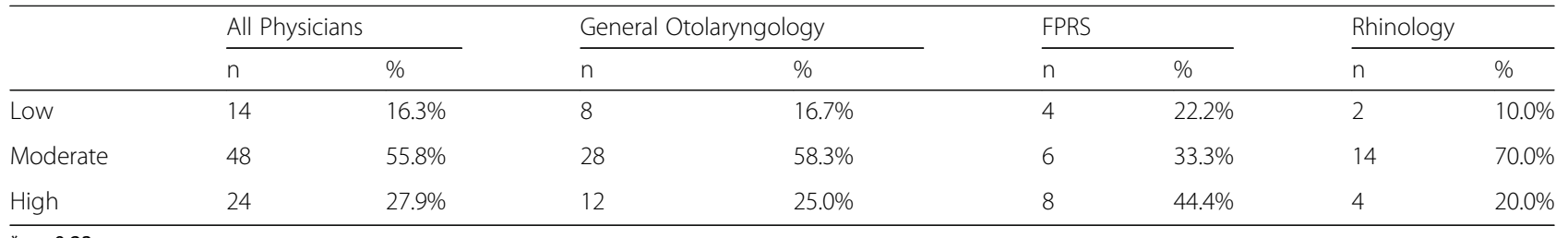

${ }^{*} p=0.23$

\section{Discussion}

This survey represents the first survey of Canadian Otolaryngologists assessing their method of diagnosis and treatment of both septal deviation as well as nasal valve collapse. Respondents in our study identified a wide variety of diagnostic methods, with the assumption that multiple tests are utilized to come to a diagnostic conclusion. Although we attempted to determine what examination physicians felt was most important, it is unclear from our survey what the relative weight each physician applies for each test when there is a discrepancy between tests. Research assessing the relative efficacy of each test as well as the combined effect of tests may assist surgeons in making evidence based decisions.

Our survey demonstrated that the Cottle Manoeuvre is both a common and important tool for NVC diagnosis. These findings are consistent with a recent systematic review, which demonstrated that the Cottle Manoeuvre was the most common method used to determine whether a patient required surgical repair [12]. This manoeuvre however, has been described in literature as non-specific, as many patients without NVC will also feel an improvement in airway patency [13, 14]. Furthermore, false negatives can occur such as in the case of osteum internum fibrosis [15]. A recent study demonstrated no change in outcome in surgical success after a septoplasty in patients with either positive or negative Cottle Maneouver [16]. These results put into question the utility of the notion that patients with a positive Cottle Maneouver, when used as a single examination, truly benefit from anything more than a septoplasty.

Interestingly, there were differences in opinions between subspecialties. FPRS indicated a higher failure rate of septoplasty alone, as well as a higher percentage of patients who require nasal valve surgery than other subspecialties. There may be multiple reasons for this discrepancy. First, the indication for referral to subspecialists may vary, such as nasal polyps referred to Rhinology versus nasal trauma referred to FPRS. Furthermore, more complicated cases of NVC may be referred to FPRS from other otolaryngologists, and both patient and physician may be more open to surgery as a final option. FPRS also perform more nasal valve surgeries, which may due to a higher number of referrals for NVC than other otolaryngologists. It is also important to note that our results may also suggest a difference in protocol for diagnosis and management of NVC between specialists.

There were some limitations to our study. The first is the response rate to our survey (Table 1). 18\% of otolaryngologists responded from $\mathrm{CSO}$, which is below the recommended guidelines of $60 \%$ to minimize nonresponse bias [17]. The CSOHNS includes many surgeons who may not perform septorhinoplasties in adults (Pediatrics, Otology, Laryngology, Head and Neck), thus our response rate is likely an underestimation of the true rate if only interested surgeons were included. External validity was also a challenge, as only 3 subspecialists

Table 6 Stratifying by speciality

\begin{tabular}{|c|c|c|c|c|c|c|c|c|c|}
\hline \multirow[t]{2}{*}{ Variable } & \multicolumn{2}{|c|}{ TOTAL } & \multicolumn{2}{|c|}{ General } & \multicolumn{2}{|l|}{ FPRCS } & \multicolumn{2}{|c|}{ Rhinology } & \multirow[b]{2}{*}{$P$-value } \\
\hline & Mean & SD & Mean & SD & Mean & SD & Mean & SD & \\
\hline Surgeons who perform Septoplasties & 86 & & 48 & & 18 & & 20 & & $>0.9$ \\
\hline Physicians Performing Surgery of the Nasal valve & 64 & & 28 & & 18 & & 18 & & 0.33 \\
\hline Number of Septoplasties / year & 71.2 & 60.7 & 54.4 & 43.9 & 109.4 & 81.8 & 46.3 & 59.5 & 0.004 \\
\hline Number of nasal valve surgeries /year & 18.4 & 17.2 & 13.1 & 13.1 & 32.4 & 21.9 & 13.3 & 10.6 & 0.004 \\
\hline Percentage of Patients with a SD who also have nasal valve collapse & 25.4 & 17.8 & 25.6 & 25.6 & 26.7 & 16.8 & 23.8 & 13.1 & 0.625 \\
\hline Percentage of patients with a SD and NVC requiring a functional rhinoplasty & 35.3 & 29.7 & 31.8 & 31.8 & 45.6 & 39.2 & 33.5 & 28.1 & 0.844 \\
\hline $\begin{array}{l}\text { Failure Rate of Septoplasty in patient with co-morbid Valve Collapse (no valve } \\
\text { surgery performed) }\end{array}$ & 33.7 & 24.8 & 34.7 & 34.7 & 44.1 & 26.3 & 17.8 & 11.0 & 0.012 \\
\hline
\end{tabular}


Table $7 \%$ with symptomatic septal deviation and NVC who require nasal valve surgery

\begin{tabular}{|c|c|c|c|c|c|c|c|c|}
\hline & \multicolumn{2}{|c|}{ TOTAL } & \multicolumn{2}{|c|}{ General } & \multicolumn{2}{|c|}{ FPRCS } & \multicolumn{2}{|c|}{ Rhinology } \\
\hline & $n$ & $\%$ & $n$ & $\%$ & $n$ & $\%$ & $n$ & $\%$ \\
\hline None & 6 & 7.0 & 6 & 12.5 & 0 & 0.0 & 0 & 0 \\
\hline$<50 \%$ & 62 & 72.1 & 34 & 70.8 & 8 & 44.4 & 20 & 100 \\
\hline$>50 \%$ & 10 & 11.6 & 4 & 8.3 & 6 & 33.3 & 0 & 0 \\
\hline All & 8 & 9.3 & 4 & 8.3 & 4 & 22.2 & 0 & 0 \\
\hline
\end{tabular}

${ }^{*} p=0.001$

replied to our survey. It is likely that survey results would be different for other subspecialists who have less experience using certain manoeuvres described in the survey. Furthermore, the majority of respondents in our study had less than 10 years of experience, which may have an impact on which diagnostic tests were performed.

The results of this study highlight the heterogeneity in terms of diagnosing valve collapse as well as the opinions on treatment indications and methods. The results of this study will assist in developing guidelines for the diagnosis of nasal valve collapse.

Future studies should aim to assess the effectiveness of diagnostic tests for NVC. If septal deviation and NVC can be accurately diagnosed, management could be optimized and prognosis may potentially improve. Interestingly, there were no responders who identified the Latera Implant as a potential treatment option when given the opportunity in open ended questions in the survey. The Latera is a novel treatment for $\mathrm{NVC}$ inserted in the office or the operating room [18]. This is a relatively new treatment and likely was not considered by those who responded to the study. It is unclear if prompted as a choice in our survey, would more surgeons have indicated their use of this treatment.
Furthermore, as anatomy does not always correlate with obstruction for septal deviation and NVC, it may be important to determine novel outcome measures to assist in management [19]. The NOSE score is one outcome measure that may be used for this particular purpose [16]. In addition, it is unknown if certain tests are applicable to both types of collapse, and more studies are needed to evaluate methods to differentiate internal and external NVC. For differentiation, one study suggested that cotton in the angle of the internal nasal valve simulating spreader grafts could be used [20]. Furthermore, although the Modified Cottle Maneouver was never explicitly discussed in literature for this particular purpose, from experience it may also be used to determine location of collapse.

\section{Conclusions}

Our findings indicate NVC is an important concern for otolaryngologists performing septoplasty. Although most physicians indicate a moderate effectiveness of the physical exam, diagnostic procedure for NVC is variable. The Cottle Maneouver is often relied on for external NVC, however its effectiveness has been challenged. Stratifying by speciality, FPRS note a higher failure rate of septoplasty alone, and believe more patients require NVC surgery than other specialists.

Table 8 Most Common Cause of Septoplasty Failure

\begin{tabular}{|c|c|c|c|c|c|c|c|c|}
\hline & \multicolumn{2}{|c|}{ TOTAL } & \multicolumn{2}{|c|}{ General } & \multicolumn{2}{|c|}{ FPRCS } & \multicolumn{2}{|c|}{ Rhinology } \\
\hline & $\mathrm{n}$ & $\%$ of Total & $n$ & $\%$ of Total & $n$ & $\%$ of Total & $n$ & $\%$ of Total \\
\hline Inadequate Septoplasty & 36 & 41.9 & 22 & 45.8 & 8 & 44.4 & 6 & 30.0 \\
\hline Nasal Valve Collapse & 22 & 25.6 & 10 & 20.8 & 6 & 33.3 & 6 & 30.0 \\
\hline Mucosal Obstruction (Turbinates/Allergies) & 6 & 7.0 & 4 & 8.3 & 0 & 0.0 & 2 & 10.0 \\
\hline Other & 6 & 7.0 & 4 & 8.3 & 0 & 0.0 & 2 & 10.0 \\
\hline Caudal Septal Deviation & 6 & 7.0 & 0 & 0.0 & 4 & 22.2 & 0 & 0.0 \\
\hline Maxillary Crest Spur & 4 & 4.7 & 2 & 4.2 & 0 & 0.0 & 2 & 10.0 \\
\hline Unrealistic Expectations & 2 & 2.3 & 3 & 6.3 & 0 & 0.0 & 0 & 0.0 \\
\hline Recurrance of Deviation & 2 & 2.3 & 1 & 2.1 & 0 & 0.0 & 2 & 10.0 \\
\hline Synechia & 2 & 2.3 & 2 & 4.2 & 0 & 0.0 & 0 & 0.0 \\
\hline
\end{tabular}




\section{Abbreviations}

AAO-HNS: American Academy of Otolaryngology - Head and Neck Surgery: CSOHNS: Canadian Society of Otolaryngology - Head and Neck Surgery; FPRS: Facial Plastics and Reconstruction Surgeons; NVC: Nasal Valve Collapse

\section{Acknowledgements}

Not applicable.

\section{Author's contributions}

YW interpreted the results, analyzed data, and wrote manuscript. JB determined study design and objectives, created survey, collected and analyzed data, and edited manuscript. Both authors read and approved the final manuscript.

\section{Funding}

None.

\section{Availability of data and materials}

Datasets are attached as an additional file.

\section{Ethics approval and consent to participate}

REB\#: \#20160194-01H.

\section{Consent for publication}

Not applicable.

\section{Competing interests}

The authors declare that they have no competing interests.

\section{Author details}

${ }^{1}$ Faculty of Medicine, University of Ottawa, Ottawa, Canada. ${ }^{2}$ Department of Otolaryngology - Head and Neck Surgery, Senior Clinical Investigator, The Ottawa Hospital Research Institute, University of Ottawa, Ottawa, Canada.

Received: 17 May 2019 Accepted: 5 December 2019

Received.17 May 2019 Accepted: 5 December

\section{References}

1. Deviated Septum [http:// www.entnet.org /content/deviated- septum]

2. Gray LP: Deviated nasal septum. Incidence and etiology. Ann Otol Rhinol Laryngol Suppl 1978, 87(3 Pt 3 Suppl 50):3-20.

3. Stewart MG, Smith TL, Weaver EM, Witsell DL, Yueh B, Hannley MT, Johnson JT. Outcomes after nasal septoplasty: results from the nasal obstruction Septoplasty effectiveness (NOSE) study. Otolaryngol Head Neck Surg. 2004; 130(3):283-90.

4. Gillman GS, Egloff AM, Rivera-Serrano CM. Revision septoplasty: a prospective disease-specific outcome study. Laryngoscope. 2014;124(6): 1290-5.

5. Wittkopf M, Wittkopf J, Ries WR. The diagnosis and treatment of nasal valve collapse. Curr Opin Otolaryngol Head Neck Surg. 2008;16(1):10-3.

6. Hong SD, Lee NJ, Cho HJ, Jang MS, Jung TY, Kim HY, Chung SK, Dhong HJ. Predictive factors of subjective outcomes after septoplasty with and without turbinoplasty: can individual perceptual differences of the air passage be a main factor? Int Forum Allergy Rhinol. 2015:5(7):616-21.

7. Becker SS, Dobratz EJ, Stowell N, Barker D, Park SS. Revision septoplasty: review of sources of persistent nasal obstruction. Am J Rhinol. 2008;22(4): 440-4.

8. Shaida AM, Kenyon GS. The nasal valves: changes in anatomy and physiology in normal subjects. Rhinology. 2000;38(1):7-12.

9. Meyer R, Jovanovic B, Derder S. All about nasal valve collapse. Aesthet Plast Surg. 1996;20(2):141-51.

10. Rhee JS, Weaver EM, Park SS, Baker SR, Hilger PA, Kriet JD, Murakami C, Senior BA, Rosenfeld RM, DiVittorio D. Clinical consensus statement: diagnosis and management of nasal valve compromise. Otolaryngol Head Neck Surg. 2010;143(1):48-59.

11. Fanous N. Anterior nasal collapse: flaccid or rigid? An approach to clinical diagnosis. J Otolaryngol. 1990;19(2):110-3.

12. Goudakos JK, Fishman JM, Patel K. A systematic review of the surgical techniques for the treatment of internal nasal valve collapse: where do we stand? Clin Otolaryngol. 2017;42(1):60-70.
13. Fung E, Hong P, Moore C, Taylor SM. The effectiveness of modified Cottle maneuver in predicting outcomes in functional rhinoplasty. Plastic surg int. 2014;2014.

14. Hamilton GS 3rd. The external nasal valve. Facial Plast Surg Clin North Am. 2017:25(2):179-94

15. Nigro CE, Nigro JF, Mion O, Mello JF Jr. Nasal valve: anatomy and physiology. Braz J Otorhinolaryngol. 2009;75(2):305-10.

16. Bonaparte JP, Campbell R. A prospective cohort study assessing the clinical utility of the Cottle maneuver in nasal septal surgery. J Otolaryngol Head Neck Surg. 2018;47(1):45

17. Bennett C, Khangura S, Brehaut JC, Graham ID, Moher D, Potter BK, J MG: Reporting Guidelines for Survey Research: An Analysis of Published Guidance and Reporting Practices. In: PLoS Med. Volume 8, edn. Edited by Jewkes R. San Francisco, USA; 2011.

18. Sanan A, Most SP. A bioabsorbable lateral Nasal Wall stent for dynamic nasal valve collapse: a review. Facial Plast Surg Clin N Am. 2019;27:367-71.

19. Bloom JD, Sridharan S, Hagiwara M, Babb JS, White WM, Constantinides M. Reformatted computed tomography to assess the internal nasal valve and association with physical examination. Arch Facial Plast Surg. 2012;14(5): $331-5$.

20. Duron JB, Nguyen PS, Jallut $Y$, Bardot J, Aiach G. Middle third of the nose and internal valve. Alar wall and external valve. Ann Chir Plast Esthet. 2014; 59(6):508-21.

\section{Publisher's Note}

Springer Nature remains neutral with regard to jurisdictional claims in published maps and institutional affiliations.
Ready to submit your research? Choose BMC and benefit from:

- fast, convenient online submission

- thorough peer review by experienced researchers in your field

- rapid publication on acceptance

- support for research data, including large and complex data types

- gold Open Access which fosters wider collaboration and increased citations

- maximum visibility for your research: over $100 \mathrm{M}$ website views per year

At BMC, research is always in progress.

Learn more biomedcentral.com/submission 